\title{
Studi Keberadaan Hiperparasitoid dalam Mempengaruhi Perilaku Imago Parasitoid pada Kutudaun, Aphis gossypii (Hemiptera: Aphididae)
}

\author{
CHANDRA IRSAN \\ Program Pascasarjana, Fakultas Pertanian,Universitas Sriwijaya
}

(diterima Januari 2008, disetujui Maret 2008)

\begin{abstract}
Study Hyperparasitoid Existing Affected to Adul Parasitoid Behavior on Aphid, Aphis gossypii (Hemiptera: Aphididae). In general, hyperparasitoid is needed for establishing food and chain webs, but in contrary, it could become a limiting factor in existing biological control program. An observation to aim positive impact of hyperparasitoid existence has been carried out. Chili plant, Capsicum annuum, Aphis gossypii, Trioxys sinensis parasitoid and Aphidencyrtus sp. were used in this observation. Results showed that hyperparasitoid existence assisted parasitoid distribution. Parasitoids were placed with hyperparasitoids enhanced parasitoid distribution or dispersion two times farther compare to without hyperparasitoids. It was concluded that dispersal behaviour of hyperparasitoid adult was a parasitoid adult's response to avoid its suppression by the hyperparasitoid and also increase parasitoid's searching ability.
\end{abstract}

KEY WORDS: parasitoid, hiperparasitoid, Aphis gossypii, Trioxys sinensis, Aphidenchyrtus sp.

\section{PENDAHULUAN}

Hiperparasitoid merupakan komponen penting yang mempengaruhi kelimpahan populasi parasitoid yang memarasit kutudaun. Tekanan hiperparasitoid pada parasitoid kutudaun dapat mencapai lebih dari 95\% (Irsan 2001a). Godfray \& Muller (1998) menyatakan bahwa dalam menentukan dinamika populasi parasitoid dan inangnya harus memperhitungkan keberadaan hiperparasitoid. Keberadaan hiperparasitoid pada koloni kutudaun erat kaitannya dengan periode waktu asosiasi parasitoid dengan koloni kutudaun. Makin lama parasitoid berasosiasi dengan koloni kutudaun akan semakin tinggi populasi hiperparasitoid yang ada di koloni kutudaun tersebut (Irsan 2001a).

Sejauh ini belum ada informasi yang menyatakan sisi positif dari keberadaan hiperparasitoid di suatu habitat. Jika diketahui sisi positif keberadaan hiperparasitoid di suatu habitat, maka akan muncul suatu teori atau gagasan baru yang akan berguna 
untuk memanfaatkan keberadaan hiperparasitoid tersebut.

Mengetahui dan memahami keberadaan serta peran hiperparasitoid dalam suatu habitat beserta pengaruhnya pada perilaku imago parasitoid ialah penting. Secara alamiah setiap penciptaan mahluk tentu saja ada tugas yang diperankan atau ada gunanya. Oleh karena belum tahu manfaatnya, maka mahluk itu dianggap tidak berguna atau merugikan. Pandangan yang negatif terhadap hiperparasitoid harus dibuktikan, karena keberadaannya di suatu habitat pasti ada manfaatnya. Peran positif hiperparasitoid yang sudah diketahui ialah sebagai komponen rantai atau jaring makanan dalam menciptakan keseimbangan populasi di suatu habitat (Brodeur 2000).

Hiperparasitoid menjadi salah satu kendala yang sangat penting dalam menentukan kelimpahan atau kemapanan parasitoid dalam menempati suatu habitat (Sullivan 1988; Sullivan \& Volkl 1999). Dalam pengendalian hayati, hiperparasitoid dikenal merugikan karena dapat menekan populasi parasitoid (Brodeur \& Rosenheim 2000). Namun hiperparasitoid itu sesungguhnya ada juga yang bermanfaat jika ia memarasit spesies hiperparasitoid yang lain atau menjadi parasitoid tersier (Memmott \& Godfray 1997; Sullivan 1988).

Hiperparasitoid dalam ekosistem dan rantai makanan memegang peran penting dalam menjaga keseimbangan populasi. Diduga keberadaannya memberikan peran positif dalam mempengaruhi perilaku imago parasitoid. Untuk memahami hal itu perlu penelitian lebih jauh mengenai hubungan antara parasitoid dengan hiperparasitoid, khususnya yang berhubungan dengan kutudaun.

Kemapanan predator dan parasitoid di suatu habitat dapat terganggu oleh tekanan parasitoid, predator atau hiperparasitoid (Sullivan \& Volkl 1999). Melalui penelitian ini diharapkan dapat diperoleh data atau informasi mengenai keberadaan hiperparasitoid dalam mempengaruhi perilaku imago parasitoid.

Hasil penelitian diharapkan dapat memperkaya khasanah ilmu, menjelaskan peran hiperparasitoid di dalam suatu habitat serta pengaruhnya terhadap parasitoid yang diparasitasinya. Data maupun informasi yang didapat dari penelitian ini diharapkan dapat menjadi acuan dalam penelitian terapan yang akan memanfaatkan parasitoid dalam pengendalian hama.

\section{BAHAN DAN METODE}

Penelitian dilakukan di dalam rumah kaca Program Pascasarjana Unsri dan Laboratorium Jurusan Hama Penyakit Tumbuhan, Fakultas Pertanian Unsri. Penelitian dilakukan dari bulan Januari sampai Oktober 2007.

Bahan dan alat yang digunakan dalam penelitian terdiri dari tanaman 
cabai (Capsicum annuum), kutudaun Aphis gossypii Glover (Hemiptera: Aphididae), parasitoid Trioxys sinensis Makauer (Hymenoptera: Aphidiidae) (Stary \& Schlinger 1967), hiperparasitoid Aphidencyrtus sp. (Hymenoptera: Encyrtidae), larutan madu, alkohol, kapas, kapsul, kain kasa, tabung reaksi, gelas benda, gelas penutup, camera, mikroskop, kuas, balsam kanada, plastik anti UV dan alat-alat tulis.

Kegiatan penelitian terdiri dari 1) persiapan, 2) mencari kutudaun, parasitoid dan hiperparasitoid, 3) memelihara tanaman inang dan kutudaun, 4) memelihara parasitoid dan hiperparasitoid, 5) pelepasan parasitoid dan hiperparasitoid ke dalam kurungan di dalam rumah kaca/plastik, 6) analisis data dan pembahasan.

Persiapan penelitian meliputi pencarian, pembelian atau pemesanan bahan-bahan dan alat-alat yang diperlukan dalam penelitian dan penyemaian benih. Selanjutnya dilakukan pembuatan alat-alat yang digunakan dalam penelitian seperti, pembuatan kurungan, rumah plastik, pengisiam polibag dan lain-lain.

Eksplorasi kutudaun, parasitoid dan hiperparasitoid dilakukan di sekitar kampus Universitas Sriwijaya. Kutudaun $A$. gossypii di lapangan cukup banyak, sehingga tidak sulit untuk menemukannya. Eksplorasi parasitoid dilakukan dengan menempatkan tanaman cabai yang telah dikoloni oleh kutudaun ke lapangan untuk menarik parasitoid maupun hiperparasitoid. Keberadaan parasitoid dicirikan dengan adanya mumi yang terbentuk, kemudian mumi dibawa ke laboratorium untuk dipelihara dan diidentifikasi. Parasitoid dikoleksi dengan memasukkan mumi ke dalam kapsul transparan untuk kemudian dibiarkan sampai imagonya muncul. Mumi kutudaun yang dikoleksi ialah mumi yang masih utuh yang belum menunjukkan adanya lubang keluar imago parasitoid maupun hiperparasitoid. Imago parasitoid dapat dibedakan dengan imago hiperparasitoid berdasarkan ukuran tubuhnya. Tubuh imago parasitoid relatif besar dibandingkan dengan hiperparasitoid dan memiliki tergit yang jelas, sebaliknya tubuh imago hiperparasitoid ukurannya lebih kecil daripada parasitoid dan tergitnya tidak kelihatan. Mumi dipelihara di laboratorium sampai muncul imago parasitoid atau hiperparasitoid. Imago parasitoid maupun hiperparasitoid yang dikoleksi kemudian diidentifikasi spesiesnya, lalu dipelihara di laboratorium dengan diberi pakan madu. Hiperparasitoid didapat dari koloni kutudaun yang sama. Jenis hiperparasitoid itu ditentukan berdasarkan bentuk mumi dan lubang keluar imago parasitoid ketika meninggalkan mumi (Irsan 2004). Lubang keluar parasitoid tepinya rata dan letaknya berada di bagian tertentu 
dari mumi, biasanya di sisi dorsal atau sisi lateral abdomen, sedangkan lubang keluar hiperparasitoid tepinya tidak rata dan letak lubang keluar tidak dibagian tertentu, lubang keluar dapat ditemukan di toraks, di sisi lateral abdomen atau sisi dorsal abdomen.

Pemeliharaan tanaman inang dan kutudaun dilakukan dengan merawat tanaman cabai yang akan digunakan dalam penelitian. Penanaman cabai dilakukan di dalam polibag ukuran 5 $\mathrm{kg}$. Cabai yang ditanam ialah 400 tanaman atau 400 polibag. Untuk percobaan digunakan 200 polibag, dan 200 polibag lainnya digunakan untuk pembiakan kutudaun, parasitoid dan hiperparasitoid. Tanaman cabai yang digunakan dalam percobaan ialah 120 tanaman yang berumur sekitar 6 minggu atau berdaun sama yaitu 10 helai. Tanaman tersebut diinfestasi dengan sejumlah kutudaun sampai terbentuk koloni. Tanaman cabai yang sudah dikoloni kutudaun A. gossypii diletakkan di dalam kurungan untuk menjamin steril dari parasitoid maupun hyperparasitoid. Selanjutnya tanaman tersebut siap diberi perlakuan.

Parasitoid dan hiperparasitoid yang digunakan dalam penelitian didapat dengan cara mengumpulkan mumi yang terbentuk pada tanaman perangkap. Untuk mendapatkan jumlah parasitoid dan hiperparasitoid yang diperlukan dilakukan dengan membiarkan tanaman cabai dikoloni kutudaun A. gossypii, apabila ada kutudaun lain selain A. gossypii, maka kutudaun itu diambil atau disingkirkan. Kemudian membiarkan kutudaun itu diparasitisasi oleh parasitoid dan hiperparastoid datang untuk memarasit parasitoid. Setelah parasitoid membentuk mumi, maka mumi itu dikumpulkan dengan cara memotong sebagian dari daun cabai yang di atasnya terdapat mumi kemudian memasukkannya ke dalam kapsul. Di dalam setiap kapsul dimasukkan 4-6 mumi dan sebelum mumi dimasukkan ke dalam kapsul, terlebih dahulu di dalam kapsul dioleskan sedikit larutan madu untuk makanan imago parasitoid atau hiperparasitoid ketika muncul dari mumi. Sehari setelah kemunculan imago, diperiksa jantan betinanya untuk dijadikan serangga yang akan digunakan dalam penelitian.

Kurungan dibuat dari rangka kayu dengan dinding dari kain kasa. Panjang kurungan $4 \mathrm{~m}$, lebar $1 \mathrm{~m}$ dan tinggi $0,6 \mathrm{~m}$. Percobaan ini menggunakan 2 buah kurungan. Di dalam setiap kurungan diletakkan 60 tanaman cabai dengan susunan 5 jajar dan 12 baris. Jarak antar tanaman cabai di dalam kurungan sekitar $15 \mathrm{~cm}$. Kurungan tersebut diletakkan di dalam rumah kaca dan ditempatkan sesuai dengan perlakuan. Parasitoid yang dimasukkan ke dalam kurungan sebanyak 10 pasang tanpa hiperparasitoid (sebagai kontrol) dan melepaskan 10 pasang parasitoid dengan 10 pasang hiperparasitoid 
(sebagai perlakuan). Imago parasitoid maupun hiperparasitoid ditempatkan pada tanaman ke-1 saat dilepaskan ke dalam kurungan. Pelepasan imago hiperparasitoid ke dalam kurungan perlakuan yang telah dimasukkan parasitoid dilakukan satu hari setelah pelepasan parasitoid.

Pengamatan dilakukan hanya sekali yaitu pada hari ke 10 atau 10 hari setelah parasitoid dilepaskan ke dalam kurungan atau 9 hari setelah hiperparasitoid dimasukkan ke dalam kurungan. Masing-masing tanaman cabai yang telah dikoloni kutudaun $A$. gossypii diperiksa untuk mengetahui pemencaran parasitoid. Dari setiap tanaman dikumpulkan semua mumi yang terbentuk kemudian dihitung. Dari mumi itu dihitung jarak pembentukan mumi dari tempat awal parasitoid dilepaskan.

Data yang diperoleh dianalisis secara deskriptif, informasi yang didapat kemudian diinterprestasikan berdasarkan data dan catatan yang diperoleh selama penelitian dan studi literatur yang menunjang.

\section{HASIL DAN PEMBAHASAN}

Kutudaun yang digunakan dalam penelitian ialah A. gossypii. Koloni kutudaun tersebut sulit dikenali berdasarkan warna karena warna tubuhnya sangat beragam. Spesies kutudaun A. gossypii dapat ditentukan berdasarkan ciri-ciri morfologi: kauda yang berambut 4 sampai 5 helai, bagian ujung sifunkuli gelap sampai hitam dan bagian pangkal sifunkuli yang menempel pada bagian dorsal abdomen lebih terang sampai coklat dan bagian dorsal abdomen imago bersayap tidak terdapat spot kecuali pada bagian sisi dorsal abdomen.

Eksplorasi parasitoid yang memarasit kutudaun A. gossypii pada tanaman cabai menemukan dua spesies parasitoid. Parasitoid itu ialah $T$. sinensis dan Aphelinus sp. (Hymenoptera: Aphelinidae). Kedua parasitoid itu dapat dibedakan melalui mumi yang terbentuk. Mumi kutudaun yang diparasit oleh parasitoid yang tergolong famili Aphidiidae berwarna abu-abu keemasan dengan bentuk agak membulat. Mumi kutudaun yang diparasit oleh parasitoid yang tergolong famili Aphelinidae bentuknya seperti kutudaun normal tetapi warnanya berubah menjadi hitam kecuali bagian kepala, antena dan tungkai.

Kelimpahan populasi kedua parasitoid tersebut di lapangan sangat berbeda. Hasil eksplorasi sebelum penelitian menunjukkan bahwa populasi Aphidiidae lebih berlimpah daripada populasi Aphelinidae. Berdasarkan hasil temuan tersebut maka yang diteliti di dalam penelitian ini ialah parasitoid yang populasinya berlimpah yaitu Aphidiidae.

Hasil penelitian menunjukkan bahwa pemencaran parasitoid dalam memarasit kutudaun dipengaruhi oleh keberadaan hiperparasitoid. Pemen- 
caran parasitoid yang berada di dalam kurungan tanpa hiperparasitoid sangat terbatas (Tabel 1). Parasitoid hanya memencar sejauh $2 \mathrm{~m}$ atau memencar sampai ke tanaman baris ke-7 dari tempat awal parasitoid dilepaskan. Secara umum dapat dinyatakan bahwa kemampuan memencar parasitoid sangat erat kaitannya dengan keberadaan hiperparasitoid.

Hasil penelitian menunjukkan bahwa pemencaran parasitoid menjadi lebih aktif jika terdapat hiperparasitoid
(Tabel 2). Keberadaan hiperparasitoid dapat memacu daya pencar parasitoid sampai 2 kali lebih jauh dibandingkan dengan tanpa keberadaan hiperparasitoid. Parasitoid memencar sampai $4 \mathrm{~m}$ atau sampai ke tanaman baris ke 12. Pada tabel 2 tersebut dapat dilihat bahwa parasitoid menjelajahi semua tanaman yang mengandung kutudaun dan meletakkan telur, tetapi telur yang diletakkan hanya sedikit. Hal itu dapat dilihat dari jumlah mumi yang terbentuk.

Tabel 1. Pemencaran parasitoid pada koloni kutudaun Aphis gossypii di dalam kurungan tanpa hiperparasitoid

\begin{tabular}{|c|c|c|c|c|c|c|c|c|c|c|c|c|c|}
\hline \multirow{3}{*}{ Ulangan/baris } & \multicolumn{12}{|c|}{ Tanaman uji ke .....*) } & \multirow{3}{*}{ Total } \\
\hline & 1 & 2 & 3 & 4 & 5 & 6 & 7 & 8 & 9 & 10 & 11 & 12 & \\
\hline & \multicolumn{12}{|c|}{ Jumlah mumi yang terbentuk pada setiap tanaman (ekor) } & \\
\hline 1 & 28 & 23 & 18 & 10 & 9 & 4 & 3 & 0 & 0 & 0 & 0 & 0 & 95 \\
\hline 2 & 21 & 27 & 16 & 11 & 9 & 5 & 2 & 0 & 0 & 0 & 0 & 0 & 91 \\
\hline 3 & 19 & 21 & 14 & 9 & 10 & 7 & 4 & 0 & 0 & 0 & 0 & 0 & 84 \\
\hline 4 & 26 & 23 & 16 & 10 & 8 & 5 & 1 & 0 & 0 & 0 & 0 & 0 & 89 \\
\hline 5 & 31 & 20 & 11 & 12 & 9 & 5 & 2 & 0 & 0 & 0 & 0 & 0 & 90 \\
\hline
\end{tabular}

Keterangan: ${ }^{*)}=$ Parasitoid dilepaskan di tanaman ke-1

Tabel 2. Pemencaran parasitoid pada koloni kutudaun Aphis gossypii di dalam kurungan yang terdapat hiperparasitoid

\begin{tabular}{|c|c|c|c|c|c|c|c|c|c|c|c|c|c|}
\hline \multirow{3}{*}{ Ulangan/baris } & \multicolumn{12}{|c|}{ Tanaman uji ke .....*) } & \multirow{3}{*}{ Total } \\
\hline & 1 & 2 & 3 & 4 & 5 & 6 & 7 & 8 & 9 & 10 & 11 & 12 & \\
\hline & \multicolumn{12}{|c|}{ Jumlah mumi yang terbentuk pada setiap tanaman (ekor) } & \\
\hline 1 & 12 & 10 & 8 & 9 & 8 & 7 & 10 & 6 & 7 & 3 & 5 & 6 & 91 \\
\hline 2 & 17 & 9 & 9 & 7 & 9 & 9 & 8 & 8 & 6 & 3 & 3 & 5 & 93 \\
\hline 3 & 14 & 9 & 8 & 6 & 8 & 3 & 7 & 6 & 7 & 3 & 1 & 3 & 75 \\
\hline 4 & 16 & 7 & 9 & 7 & 7 & 8 & 6 & 7 & 7 & 5 & 4 & 5 & 88 \\
\hline 5 & 17 & 9 & 7 & 11 & 8 & 5 & 7 & 5 & 6 & 5 & 3 & 5 & 89 \\
\hline
\end{tabular}

Keterangan: *) $=$ Parasitoid dilepaskan dari tanaman ke-1 
Berdasarkan hasil penelitian tersebut dapat diketahui bahwa keberadaan hiperparasitoid memberikan dampak positif dalam mendorong kinerja parasitoid untuk memencar. Diduga pemencaran parasitoid tersebut disebabkan perilaku parasitoid untuk menghindarkan dari tekanan hiperparasitoid. Imago parasitoid berusaha menghindari tekanan hiperparasitoid. Irsan (2001b) menyatakan bahwa hiperparasitoid dapat memarasit parasitoid sampai 92\%. Hasil penelitian menunjukkan bahwa imago parasitoid meletakkan telur cukup banyak di satu tanaman, hal itu dapat diketahui melalui mumi yang terbentuk pada satu tanaman. Setelah selesai menjelajahi tanaman pertama, imago parasitoid itu pindah ke tanaman kedua yang ada di dekatnya dan kembali menjelajahi setiap bagian tanaman untuk mencari kutudaun yang akan diletaki telur atau dijadikan inang dan seterusnya (Tabel 1). Pemencaran terhenti sampai ke tanaman baris ke-7, terhentinya pemencaran tersebut diduga erat kaitannya dengan kandungan telur yang terdapat di dalam tubuh imago. Diduga setelah sampai pada tanaman ke-7 imago telah kehabisan telur atau tidak ada telur yang akan diletakkan lagi. Secara umum jumlah telur yang dikandung oleh parasitoid relatif sama. Belum ada informasi mengenai jumlah telur yang siap diletakkan pada saat imago T. sinensis keluar dari mumi.

Parasitoid yang berada di dalam kurungan yang terdapat hiperparasitoid menjadi lebih lincah. Imago parasitoid mula-mula meletakkan telur pada tanaman ke-1, jumlah telur yang diletakkan atau mumi yang terbentuk cukup banyak. Kemudian dimasukkan hiperparasitoid, maka kutudaun memencar ke tanaman baris ke-2 dan meletakkan telur, namun telur yang diletakkan sedikit dan pindah lagi ke tanaman baris ke-3 dan seterusnya. Pada tabel 2 dapat dilihat bahwa imago parasitoid menjelajahi semua tanaman yang ada dan meletakkan telur, namun jumlah telur yang diletakkan relatif sedikit.

Hasil penelitian ini menunjukkan bahwa jumlah mumi yang terbentuk dari masing-masing perlakuan relatif sama. Artinya masing-masing imago parasitoid membawa telur yang relatif sama. Secara umum jumlah mumi yang terbentuk di dalam kurungan yang terdapat hiperparasitoid lebih sedikit dibandingkan dengan di dalam kurungan tanpa hiperparasitoid. Diduga hal itu erat kaitannya dengan aktivitas imago dalam memencar. Aktivitas memencar telah mengurangi jumlah telur yang dapat diletakkan. Berkurangnya jumlah telur yang diletakkan itu diduga erat kaitannya dengan pemanfaatan energi untuk menjelajahi semua tanaman yang ada 
di dalam kurungan. Menurut Quicke (1997) parasitoid yang tergolong Aphidiidae seperti T. sinensis termasuk parasitoid yang memiliki karakter reproduksi synovigenic.

Berdasarkan hasil penelitian ini terlihat bahwa keberadaan hiperparasitoid memberikan suatu dampak positip dalam meningkatkan kemampuan memencar parasitoid. Hasil penelitian ini memberikan gambaran tentang adanya peluang untuk memanfaatkan hiperparasitoid dalam memacu kinerja parasitoid. Stary (1988) menyatakan bahwa pergerakan parasitoid dalam menemukan inang erat kaitannya dengan odor atau bau, sehingga bau yang muncul dari asosiasi antara serangga inang dengan tumbuhan inang menjadi bagian penting dan menentukan bagi parasitoid dalam menemukan inang. Hiperparasitoid menemukan inangnya erat kaitannya dengan interaksi antara parasitoid dan serangga inang (Sullivan \& Volkl 1999). Tingginya populasi hiperparasitoid yang datang ke suatu habitat inang erat kaitannya dengan kepadatan populasi parasitoid (Brodeur 2000a).

Parasitisasi hiperparasitoid pada parasitoid yang memarasit kutudaun dapat terjadi sebelum terbentuk mumi dan ada yang dapat memarasit setelah terbentuk mumi (Sullivan 1988). Keberadaan embun madu dapat menjadi pemicu kehadiran parasitoid dan hiperparasitoid pada koloni kutudaun. Imago hiperparasitoid datang ke koloni kutudaun mula-mula hanya mencari pakan berupa embun madu yang dikeluarkan oleh kutudaun (Irsan 2001a). Kutudaun mengeluarkan embun madu merupakan suatu mekanisme mendapatkan cairan tanaman yang berkualitas sebagai bahan makanan. Kutudaun akan membuang sebagian kelebihan cairan yang masuk ke dalam tubuhnya berupa embun madu (Blackman \& Eastop 2000).

Secara umum dapat dinyatakan bahwa kinerja parasitoid dan hiperparasitoid sangat erat kaitannya dengan bau atau odor. Jadi peran positif keberadaan hiperparasitoid sesungguhnya memberikan suatu peluang untuk dimanfaatkan sebagai pendorong pergerakan parasitoid menjelajah semua tempat yang mengandung serangga inang. Suatu peluang penelitian lanjutan yang mungkin dilakukan ialah mengambil bau dari hiperparasitoid. Jika itu dapat dilakukan maka bau hiperparasitoid itu dapat diberikan di habitat yang dilepas parasitoid. Keberadaan bau hiperparasitoid itu dapat diartikan oleh imago parasitoid bahwa di sekitarnya terdapat hiperparasitoid. Dengan demikian kinerja parasitoid meningkat dengan tanpa resiko menekan populasi parasitoid. Sungguh itu merupakan suatu tantangan yang menarik untuk diteliti dan dikaji lebih lanjut. 


\section{KESIMPULAN}

Hiperparasitoid dapat meningkatkan kinerja atau kemampuan memencar parasitoid sampai dua kali lebih jauh dibandingkan dengan tanpa hiperparasitoid. Diduga peningkatan perilaku memencar parasitoid tersebut merupakan upaya imago parasitoid untuk menghindari tekanan hiperparasitoid.

\section{SARAN}

Perlu dilakukan penelitian atau kajian lanjutan untuk mengetahui perilaku imago parasitoid secara detail ketika berada di dalam habitat yang mengandung hiperparasitoid. Jika mungkin dilakukan penelitian untuk mengisolasi dan memanfaatkan odor atau bau hiperparasitoid. Pemanfaatan bau tersebut diharapkan dapat meningkatkan kinerja parasitoid dalam mencari atau menemukan inang.

\section{UCAPAN TERIMA KASIH}

Terima kasih kami sampaikan kepada DP2M Dikti yang telah membiayai penelitian saya ini melalui Penelitian Fundamental tahun 2007 dan Dr. Ir. Arinafril yang telah membantu mengoreksi tulisan ini.

\section{DAFTAR PUSTAKA}

Blackman RL, Eastop FV. 2000. Aphids on the world's crops: an identification guide. John Wiley and Sons., Chichester. 466 p.
Brodeur J. 2000. Host specificity and trophic relationships of hyperparasitoids. In: Hochberg ME, Iver AR, (Eds.), Parasitoid Population Biology. Princeton Univ. Princeton. p 163-183.

Godfray HCJ, Muller CB. 1998. Host-parasitoid dynamics. In: Dempster JP, Mclean IFG (Eds.), Insect Populations in teory and in practice. Dordrecht, Kluwer Academic Publishers. p 135-165.

Irsan C. 2001a. Hiperparasitoid pada parasitoid kutudaun Aphis gossypii (Glover) (Aphididae: Homoptera) di Tanaman Spatodea sp. Didalam: Prosiding Simposium Pengendalian Hayati Serangga, Sukamandi, 14-15 Maret 2001. hlm. 59-62.

Irsan C. 2001b. Parasitisasi parasitoid sekunder pada parasitoid primer kutudaun (Homoptera:

Aphididae). Di dalam: Prosiding Seminar Nasional Pertanian Berkelanjutan, Bandar Lampung 26-27 Juni 2001.

Irsan C. 2004c. Parasitisasi Diaeretiella rapae (M'Intosh) dan Aphelinus sp. Pada kutudaun Myzus persicae (Sulzer) (Homoptera: Aphididae). [Disertasi]. Sekolah Pascasarjana Institut Pertanian Bogor, Bogor.

Irsan C, Hidayat P. 2003. Perilaku Diaeretiella sp. (Hymenoptera: Aphidiidae) dan Aphelinus sp. (Hymenoptera: Aphelinidae) dalam memarasit kutudaun Myzus persicae (Sulzer) (Homoptera: Aphidiidae). Makalah disampaikan pada Kongres VI Perhimpunan Entomologi Indonesia dan Simposium, 
Entomologi 2003, Cipayung Bogor 5-7 Maret 2003.

Memmott J, Godfray HCJ. 1997. Parasitoid webs In: LaSalle, Gauld (Eds.), Hymenoptera and Biodiversity. CAB International, Wallingford U.K. p 217-234.

Quicke DLJ. 1997. Parasitic Waps. Chapman \& Hall. London

Stary P, Schlinger EI. 1967. A Revision of the far East Asian Aphidiidae (Hymenoptera)
Series Entomologica Vol.3. Dr. W. Junk - Den Haag.

Sullivan DJ. 1988. Hyperparasitoid. In: Minks AK, Harrewijn P. (Eds.), Aphids: Their Biology, Natural Enemies and Control. Vol 2B. Elsevier: Amsterdam. p. 189203

Sullivan DJ, Volkl W. 1999. Hyperparasitism: multitropic, ecology and behavior. Annu. Rev. Entomol. 44: 291-315. 